\title{
Fisioterapia após substituição artroscópica do ligamento cruzado cranial em cães. I - avaliação clínica, radiográfica e ultrassonográfica
}

\author{
[Physiotherapy after arthroscopic repair of the cranial cruciate ligament in dogs. \\ I - clinical, radiographic, and ultrasonographic evaluation] \\ L.A.L. Muzzi ${ }^{1}$, C.M.F. Rezende ${ }^{2}$, R.A.L. $M u z z i^{1}$ \\ ${ }^{1}$ Departamento de Medicina Veterinária - UFLA \\ Caixa Postal 3037 \\ 37200-000 - Lavras, MG \\ ${ }^{2}$ Escola de Veterinária - UFMG - Belo Horizonte, MG
}

\begin{abstract}
RESUMO
Foram avaliadas a aplicabilidade da cirurgia artroscópica na substituição do ligamento cruzado cranial (LCC) e o efeito da fisioterapia pós-operatória, por meio de exames clínicos, radiográficos e ultrassonográficos, em 16 cães sem raça definida, machos, com pesos entre 19,2 e 26,3kg, submetidos à ruptura experimental do LCC e subsequente substituição deste ligamento pelo enxerto autógeno da fascia lata. Os animais foram distribuídos em dois grupos de oito cada: no grupo I os cães foram submetidos ao programa de fisioterapia pós-operatória e no grupo II à imobilização temporária do membro. Por meio dos exames citados, não foram verificadas diferenças significativas entre os dois grupos, e ambos demonstraram sinais de processo articular degenerativo. A função do membro foi avaliada com auxílio da plataforma de força, e os animais do grupo I apresentaram melhor apoio do membro operado durante o período de reabilitação. Conclui-se que a cirurgia artroscópica é uma técnica eficaz para substituição do LCC em cães, apesar de não impedir o desenvolvimento da doença articular degenerativa, e que a fisioterapia permite recuperação mais rápida no apoio do membro durante o período de reabilitação.
\end{abstract}

Palavras-chave: cão, ortopedia, joelho, ligamento cruzado

\begin{abstract}
The reconstruction of experimentally ruptured cranial cruciate ligament (CCL) under arthroscopic guidance and the effects of an early postoperative rehabilitation program by clinical, radiographic, and ultrasonographic exams were evaluated. Sixteen male mongrel dogs weighing from 19.2 to $26.3 \mathrm{~kg}$ had the CCL experimentally ruptured and the stifle joint was stabilized by the use of an intracapsular arthroscopical technique with fascia lata as an autogenous graft. Eight dogs were included in a postoperative physiotherapy group and the other eight in a temporary immobilization group. From serial clinical, radiographic, and ultrasonographic examinations, no differences between groups were observed, although all dogs had showed signs of degenerative joint disease. Limb function was determined after surgery using force platform analysis, and the animals from physiotherapy group had significantly better results during rehabilitation period. It can be concluded that arthroscopic surgery for reconstruction of the cranial cruciate ligament is an efficient method to be used in dogs, in spite of not preventing the degenerative joint disease, and the physiotherapy has beneficial effects on early limb function during the rehabilitation period.
\end{abstract}

Keywords: dog, orthopedics, stifle joint, cruciate ligament

Recebido em 2 de julho de 2008

Aceito em 14 de abril de 2009

E-mail: lalmuzzi@ufla.br

Apoio: FAPEMIG 


\section{INTRODUÇÃO}

A ruptura do ligamento cruzado cranial (LCC) é uma das alterações ortopédicas mais frequentes no cão (Hayashi et al., 2004). A perda funcional do LCC leva à instabilidade articular, resultando em lesões degenerativas na articulação femorotibiopatelar (FTP) e desuso do membro (Glyde et al., 2002). São descritas várias técnicas cirúrgicas para substituição do ligamento rompido, objetivando restaurar a estabilidade da articulação. A substituição artroscópica do LCC em cães encontra-se em fase de desenvolvimento e oferece o benefício de reduzir o trauma aos tecidos moles periarticulares (Kudnig, 2000). Após a cirurgia intra-articular, a fisioterapia pode ser empregada na reabilitação do paciente, aumentando a resistência dos tecidos e promovendo o retorno precoce às atividades normais (Taylor et al., 1998; Marsolais et al., 2002).

Este trabalho teve como objetivos: avaliar a aplicabilidade e a eficácia da cirurgia artroscópica na substituição do LCC em cães e, por meio de exames clínicos, radiográficos e ultrassonográficos, estudar o efeito da fisioterapia pós-operatória na articulação e no retorno da função do membro após a intervenção cirúrgica.

\section{MATERIAL E MÉTODOS}

Este estudo experimental foi aprovado pelo Comitê de Ética em Experimentação Animal (CETEA) da Universidade Federal de Minas Gerais. Foram utilizados 16 cães hígidos, machos, adultos jovens, não-castrados, sem raça definida, com pesos entre 19,2 e 26,3kg. Em todos os cães, a articulação FTP do membro direito foi submetida à intervenção cirúrgica, permanecendo o membro contralateral intacto. Inicialmente, realizou-se a preparação do retalho da fascia lata, por meio de incisão craniolateral retilínea na pele, que se estendeu do terço proximal ao terço distal do fêmur, para criar um retalho da fascia lata, com aproximadamente $2,0 \mathrm{~cm}$ de largura em toda sua extensão. $\mathrm{O}$ enxerto foi mantido pediculado na extremidade distal, na altura da fabela lateral.

A articulação foi puncionada medial ao ligamento patelar e dilatada com a infusão de $20 \mathrm{~mL}$ de Ringer lactato. Foi realizada uma incisão da pele, de aproximadamente $5 \mathrm{~mm}$, lateral ao terço médio do ligamento patelar, aprofundada até perfurar a cápsula articular, onde se introduziu a bainha artroscópica ${ }^{1}$ guiada por trocarte rombo. O sistema de irrigação ${ }^{2}$ foi conectado à bainha artroscópica, sendo o trocarte removido e substituído pelo artroscópio ${ }^{3}$ acoplado à câmera ${ }^{4}$. Após a inspeção artroscópica das estruturas intra-articulares, foi realizada uma incisão da pele, de aproximadamente $5 \mathrm{~mm}$, medial ao terço médio do ligamento patelar, aprofundada até perfurar a cápsula articular. Sob visibilização artroscópica, seccionou-se o LCC com o auxílio de tesoura ${ }^{5}$ introduzida através da incisão medial. Os restos do LCC seccionado foram parcialmente removidos com o auxílio de pinça de biopsia ${ }^{6}$ introduzida através do mesmo orifício medial.

Imediatamente após a secção e remoção parcial do LCC, realizou-se a substituição deste ligamento pelo enxerto autógeno da fascia lata, guiada por artroscopia. Foi feito um túnel tibial, partindo da superfície medial proximal da tíbia, a cerca de $2,5 \mathrm{~cm}$ distal do platô tibial, emergindo no ponto da inserção tibial do LCC. O túnel tibial foi perfurado com broca de $3,5 \mathrm{~mm}$ de diâmetro utilizando-se uma furadeira pneumática. Sob visibilização artroscópica, um guia de fio foi introduzido na articulação pelo orifício parapatelar medial e direcionado na fossa intercondilar, emergindo imediatamente caudal à fabela lateral. No guia de fio, foi introduzido um fio de aço de $1,0 \mathrm{~mm}$ de diâmetro usado para apreender a extremidade proximal do enxerto e tracioná-la para o interior da articulação (Fig. 1A).

Com auxílio do fio de aço introduzido na articulação pelo orifício tibial, o enxerto foi apreendido e conduzido através do túnel tibial, exteriorizando-se na superfície medial proximal da tíbia (Fig. 1B). Seguiu-se a colocação de parafuso $^{7}$ e arruela $^{8}$ na superfície da tíbia, imediatamente distal à saída do enxerto. Com o

\footnotetext{
${ }^{1}$ Karl Storz - Alemanha.

${ }^{2}$ Artro-pump - Karl Storz - Alemanha

${ }^{3}$ Aparelho artroscópico 2,7mm $\varnothing, 30^{\circ}$ - Karl Storz -

Alemanha.

Unidade de Câmera Telecam SL - Karl Storz - Alemanha.

${ }^{5}$ Tesoura artroscópica - Karl Storz - Alemanha.

${ }^{6}$ Pinça artroscópica de biopsia - Karl Storz - Alemanha.

${ }^{7}$ Parafuso ortopédico cortical 3,5mm - Baumer - Brasil.

${ }^{8}$ Arruela ortopédica côncava $12 \mathrm{~mm} \varnothing$ - Baumer - Brasil.
} 
membro em posição neutra, a extremidade livre do enxerto foi tracionada e passada ao redor do parafuso em uma volta completa. Mantendo-se o enxerto sob tensão, o parafuso foi apertado, fixando o enxerto entre a arruela côncava e o osso. Foram aplicadas quatro suturas simples separadas com fio monofilamentar absorvível ${ }^{9} 2$ 0 unindo a extremidade livre do enxerto àquela fixada (Fig. 1C), seccionando-se o excedente do enxerto. Os tecidos incisados foram aproximados de forma rotineira. No pós-operatório, foi administrado carprofeno ${ }^{10}(2,2 \mathrm{mg} / \mathrm{kg}$, via oral) a cada 12 horas, durante sete dias. Os animais foram mantidos em canis individuais tipo solário e distribuídos aleatoriamente em dois grupos de oito. Cada grupo foi submetido a um protocolo diferente de atividades no período pósoperatório.

Os cães do grupo I foram submetidos a um programa fisioterápico após a substituição do LCC, estruturado com base na literatura consultada (Hodges e Palmer, 1993; Johnson et al., 1997; Millis e Levine, 1997; Taylor et al., 1998; Marsolais et al., 2002) e nos dados obtidos no pré-experimento. $\mathrm{O}$ protocolo fisioterápico foi dividido em três fases principais e estendeu-se por 60 dias. Na primeira fase, de pós-operatório imediato, do primeiro ao terceiro dia, realizou-se a crioterapia com colocação de compressas com gelo sobre a articulação FTP, durante 10 minutos, duas vezes ao dia. Do terceiro ao $14^{\circ}$ dia de pós-operatório, promoveram-se a eletroterapia por estimulação elétrica ${ }^{11}$ (corrente farádica, com dosagem de $14 \mathrm{~mA}$ de pico) dos músculos semitendinoso, bíceps femoral e vasto lateral, durante cinco minutos em cada grupo muscular, no total de 15 minutos, uma vez ao dia, e a cinesioterapia passiva, com movimentação passiva do membro, em movimentos de flexão e extensão da articulação FTP, durante 10 minutos, 20 ciclos por minuto, uma vez ao dia. Na segunda fase, de restabelecimento inicial, do $15^{\circ}$ ao $28^{\circ}$ dia de pós-operatório, realizaram-se a cinesioterapia passiva, com movimentação passiva do membro, em movimentos de flexão e extensão da articulação FTP, durante 10 minutos, 30 ciclos por minuto, uma vez ao dia, e a cinesioterapia ativa, com caminhadas em terreno plano com solo de areia, na distância de 500 metros durante 10 minutos, uma vez ao dia. Na terceira fase, de restabelecimento avançado, do $29^{\circ}$ ao $42^{\circ}$ dia de pós-operatório, realizaram-se a cinesioterapia ativa, com caminhadas em terreno plano com solo de areia, na distância de 750 metros durante 10 minutos, uma vez ao dia, e a cinesioterapia ativa de resistência, com exercícios de subir e descer escadas, em 750 degraus durante 10 minutos, uma vez ao dia. Do $43^{\circ}$ ao $60^{\circ}$ dia de pós-operatório, realizou-se a cinesioterapia ativa de resistência, com exercícios de subir e descer escadas, em 1500 degraus durante 20 minutos, uma vez ao dia.

Os cães do grupo II foram mantidos nos canis individuais, onde permaneceram por 15 dias com imobilização temporária do membro por meio da muleta de Thomas modificada. Após esse período, os animais permaneceram nos canis sem atividades físicas específicas.

O exame ortopédico foi realizado na fase préoperatória e semanalmente após a cirurgia. As características de claudicação e apoio do membro, presença de crepitação e grau de sensibilidade dolorosa à movimentação da articulação FTP foram avaliados por meio de um sistema de pontuação (Tab. 1). A mensuração da circunferência da coxa foi realizada em três pontos diferentes ao longo do eixo femoral: terço distal do fêmur (imediatamente proximal à patela), terço proximal do fêmur $(3 \mathrm{~cm}$ distal ao trocânter maior) e terço médio do fêmur (ponto médio entre os dois anteriores), utilizando-se fita métrica convencional. A amplitude de movimentos da articulação FTP foi obtida medindo-se os ângulos máximos de extensão e flexão, com goniômetro universal. A estabilidade articular pós-operatória foi avaliada pela mensuração do deslocamento cranial da tíbia em relação ao fêmur (teste da gaveta), com o membro em extensão e em semiflexão. Cada variável foi medida três vezes, sendo considerado o valor médio. Todos os parâmetros analisados ao exame ortopédico foram avaliados no membro operado e no membro contralateral normal.

\footnotetext{
${ }^{9}$ Monocryl - Ethicon - Brasil.

${ }^{10}$ Rimadyl 75mg - Laboratórios Pfizer Ltda. - Brasil.

${ }^{11}$ Aparelho Dyadinaction Master Line - KW Eletrônica Brasil.
} 

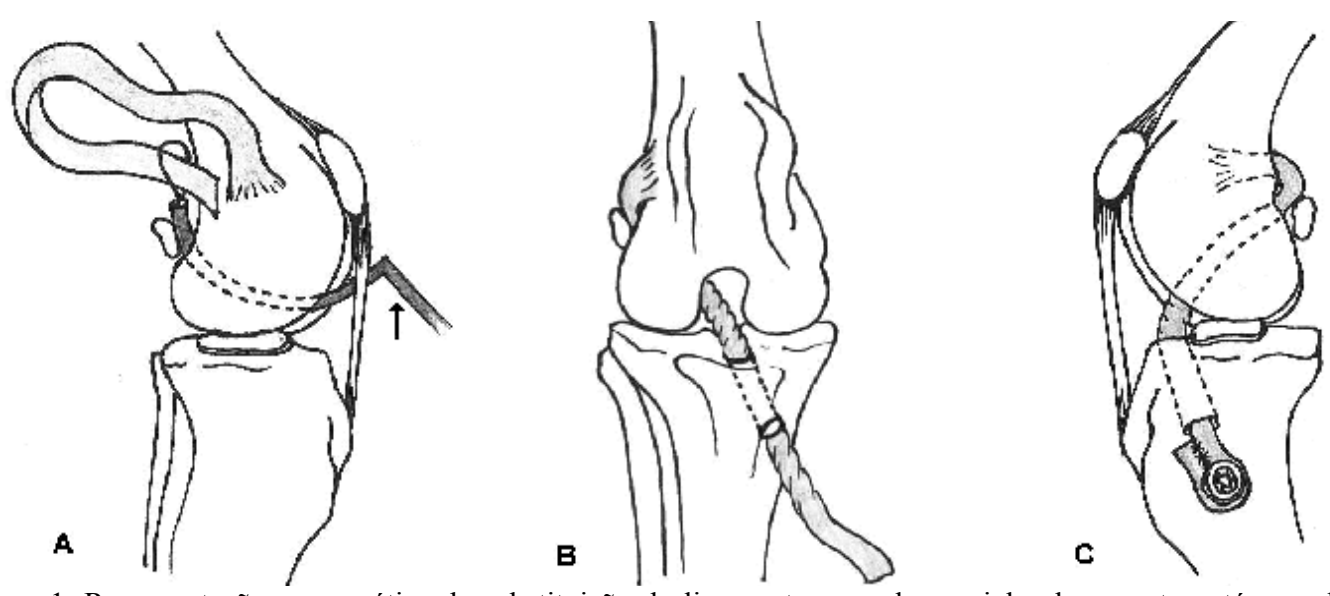

Figura 1. Representação esquemática da substituição do ligamento cruzado cranial pelo enxerto autógeno de fascia lata. A) vista lateral da articulação femorotibiopatelar direita. O guia de fio (seta) é introduzido na articulação medialmente ao ligamento patelar, passando pela fossa intercondilar e emergindo imediatamente caudal à fabela lateral. Com auxílio de um fio de aço introduzido no guia de fio, a extremidade livre do enxerto é apreendida e tracionada para o interior da articulação. B) vista cranial da articulação femorotibiopatelar direita. O enxerto pediculado de fascia lata é tracionado torcido entre os côndilos femorais e através do túnel ósseo previamente perfurado na tíbia, exteriorizando-se na superfície medial proximal da tíbia. C) vista medial da articulação femorotibiopatelar direita. A extremidade livre do enxerto é fixada na superfície medial proximal da tíbia com auxílio de parafuso e arruela côncava. A parte livre do enxerto é suturada ao segmento fixado utilizando-se suturas simples separadas.

Tabela 1. Sistema de pontuação para características de claudicação e apoio do membro, presença de crepitação e grau de sensibilidade dolorosa avaliados ao exame ortopédico de cães submetidos à fisioterapia ou imobilização temporária, após a substituição artroscópica do ligamento cruzado cranial

\begin{tabular}{cl}
\hline Pontuação & \multicolumn{1}{c}{ Claudicação e apoio do membro } \\
\hline 1 & $\begin{array}{l}\text { Apoio normal do membro em estação. Ausência de claudicação ao caminhar e correr. } \\
\text { Alívio discreto do suporte de peso no membro, com apoio total dos dígitos e coxim plantar em estação. } \\
\text { Ausência de claudicação ao caminhar e claudicação intermitente (discreta) ao correr. } \\
\text { Alívio do suporte de peso no membro, com apoio total dos dígitos e apoio parcial do coxim plantar em } \\
\text { estação. Claudicação intermitente (discreta) ao caminhar e claudicação frequente (moderada) ao correr. }\end{array}$ \\
3 & $\begin{array}{l}\text { Acentuada transferência do suporte de peso do membro, com apoio dos dígitos e ausência de apoio do coxim } \\
\text { plantar em estação. Claudicação moderada ao caminhar e acentuada ao correr, tocando a ponta dos dígitos. } \\
\text { Apoio com a ponta dos dígitos ou elevação do membro em estação. Claudicação acentuada ao caminhar e } \\
\text { correr, tocando a ponta dos dígitos ou sem suporte de peso. }\end{array}$ \\
&
\end{tabular}

Presença de crepitação

(Movimentos de flexão e extensão da articulação femorotibiopatelar)

\begin{tabular}{cl}
\hline Pontuação & \multicolumn{1}{c}{ Descrição } \\
\hline 1 & Ausente. \\
2 & $\begin{array}{l}\text { Crepitação discreta: presença de crepitação discreta nos extremos de flexão e extensão da articulação } \\
\text { femorotibiopatelar. }\end{array}$ \\
3 & $\begin{array}{l}\text { Crepitação moderada: presença de crepitação intermitente ao movimentar a articulação femorotibiopatelar. } \\
\text { Crepitação acentuada: presença de crepitação intensa e constante em toda a amplitude de movimentos da } \\
\text { articulação femorotibiopatelar. }\end{array}$
\end{tabular}

Presença de sensibilidade dolorosa

(Movimentos de flexão e extensão da articulação femorotibiopatelar)

\begin{tabular}{cl}
\hline Pontuação & \multicolumn{1}{c}{ Descrição } \\
\hline 1 & Sem sinais de dor. \\
2 & Dor discreta: ato de virar a cabeça para reconhecimento. \\
3 & Dor moderada: ato de puxar o membro ao movimentar a articulação femorotibiopatelar. \\
4 & $\begin{array}{l}\text { Dor acentuada: ato de vocalizar e tornar-se agressivo, não permitindo a movimentação da articulação } \\
\text { femorotibiopatelar. }\end{array}$ \\
\hline
\end{tabular}


Com a utilização da plataforma de força ${ }^{12}$, avaliou-se o apoio dos membros dos cães no préoperatório e aos 30, 60, 90 e 120 dias após a cirurgia. Os animais foram posicionados em estação, permanecendo com os membros pélvicos apoiados no centro de cada uma das placas, não sendo mensurado o apoio dos membros torácicos. Pelo sistema computadorizado, quantificou-se a porcentagem de peso corpóreo apoiado pelos membros pélvicos, mantendo-se o paciente estático. Para cada avaliação individual, foram obtidas oito medidas, sendo considerado o valor médio.
Os cães foram tranquilizados com acepromazina $^{13}(0,1 \mathrm{mg} / \mathrm{kg}, \mathrm{IV})$ e submetidos aos exames radiográficos das articulações FTP no pré-operatório imediato e aos 30,60, 90 e 120 dias após a cirurgia. Foram obtidas imagens radiográficas de ambos os membros, nas incidências mediolateral e craniocaudal. As radiografias foram avaliadas quanto à presença de alterações articulares, como efusão articular, formação de osteófitos periarticulares e/ou intraarticulares e esclerose do osso subcondral. As características avaliadas ao exame radiográfico foram classificadas por meio de um sistema de pontuação (Tab. 2).

Tabela 2. Sistema de pontuação para características avaliadas ao exame radiográfico da articulação femorotibiopatelar de cães submetidos à fisioterapia ou imobilização temporária, após a substituição artroscópica do ligamento cruzado cranial

\begin{tabular}{cl}
\hline Pontuação & \multicolumn{1}{c}{ Descrição } \\
\hline 1 & $\begin{array}{l}\text { Sem alterações na articulação femorotibiopatelar. } \\
\text { Alterações discretas: efusão articular, discreta formação de osteófitos periarticulares (extremidades da } \\
\text { patela, superfície caudal dos côndilos da tíbia). }\end{array}$ \\
3 & $\begin{array}{l}\text { Alterações moderadas: efusão articular, moderada formação de osteófitos periarticulares (extremidades } \\
\text { da patela, superfície caudal dos côndilos da tíbia, cristas trocleares do fêmur, fabelas, cabeça da fíbula, }\end{array}$ \\
& $\begin{array}{l}\text { superfícies medial e/ou lateral dos côndilos femorais). } \\
\text { Alterações acentuadas: efusão articular, acentuada formação de osteófitos periarticulares (extremidades } \\
\text { da patela, superfície caudal dos côndilos da tíbia, cristas trocleares do fêmur, fabelas, cabeça da fíbula, } \\
\text { superfícies medial e/ou lateral dos côndilos femorais), formação de osteófitos intra-articulares (superfície } \\
\text { articular do platô tibial e fossa intercondilar) e esclerose do osso subcondral. }\end{array}$ \\
\hline
\end{tabular}

O exame ultrassonográfico da articulação FTP de ambos os membros foi realizado no préoperatório e aos 30, 60, 90 e 120 dias após a cirurgia, utilizando-se um aparelho ultrassonográfico $^{14}$ com modo bidimensional e transdutor linear de $7,5 \mathrm{MHz}$. A articulação FTP foi examinada nos planos sagital e transversal, nas regiões suprapatelar, infrapatelar, lateral e medial, e as imagens ultrassonográficas avaliadas quanto à presença de alterações articulares, como distensão do recesso suprapatelar, osteófitos nos côndilos femorais, osteófitos nas extremidades da patela e fabelas, irregularidades nas bordas trocleares e na superfície articular da tíbia e protrusão dos meniscos. Os achados das alterações articulares foram classificados por meio de um sistema de pontuação (Tab. 3).

Tabela 3. Sistema de pontuação para características avaliadas ao exame ultrassonográfico da articulação femorotibiopatelar de cães submetidos à fisioterapia ou imobilização temporária, após a substituição artroscópica do ligamento cruzado cranial

\begin{tabular}{cl}
\hline Pontuação & \multicolumn{1}{c}{ Descrição } \\
\hline 1 & Sem alterações na articulação femorotibiopatelar. \\
2 & $\begin{array}{l}\text { Alterações discretas: recesso suprapatelar distendido, discretas irregularidades nas superfícies medial e/ou } \\
\text { lateral dos côndilos femorais. }\end{array}$ \\
3 & $\begin{array}{l}\text { Alterações moderadas: recesso suprapatelar distendido, moderadas irregularidades nas superfícies medial e } \\
\text { lateral dos côndilos femorais, osteófitos na extremidade distal da patela e nas fabelas. }\end{array}$ \\
4 & $\begin{array}{l}\text { Alterações acentuadas: recesso suprapatelar distendido, acentuadas irregularidades nas superfícies medial e } \\
\text { lateral dos côndilos femorais, osteófitos na extremidade distal da patela e nas fabelas, irregularidades na } \\
\text { superfície articular do platô tibial, protrusão dos meniscos. }\end{array}$ \\
\hline
\end{tabular}

\footnotetext{
${ }^{12}$ Equipamento Balance Master System 7.0 - Neurocon Inc. - EUA.

${ }^{13}$ Acepran $1 \%$ - Univet S.A. - Brasil.

${ }^{14}$ Aparelho Ultrassonográfico FF Sonic UF 4500 - Fukuda Denshi - Japão.
} 
A análise estatística foi realizada com auxílio do sistema SAEG (Euclydes, 1999). Para as variáveis avaliadas semanalmente, utilizou-se o teste Scott-Knott para comparação de médias. Para as variáveis avaliadas mensalmente, utilizou-se o teste Student-Newman-Keuls para comparação de médias. Os dados obtidos por meio de avaliações de caráter qualitativo foram submetidos ao teste Kruskal-Wallis para comparações múltiplas entre médias. Em todas as variáveis analisadas, foram consideradas significativas as diferenças com probabilidade de $5 \%(\mathrm{P} \leq 0,05)$.

\section{RESULTADOS}

Baseando-se no sistema de pontuação préestabelecido para avaliação da claudicação e apoio do membro sobre o solo, todos os animais apresentaram grau de claudicação mais intenso e menor apoio do membro operado nas primeiras quatro semanas de pós-operatório. Ao longo das semanas, ambos os grupos demonstraram melhora progressiva na deambulação e apoio do membro, apresentando somente claudicação discreta à $17^{\mathrm{a}}$ semana após a cirurgia. Não se observou diferença estatística significativa entre os grupos da fisioterapia e da imobilização temporária quanto à claudicação e ao apoio do membro operado.

Quanto à crepitação durante os movimentos de flexão e extensão da articulação FTP operada, não se verificou diferença significativa entre os grupos durante as semanas avaliadas. Entretanto, observou-se clinicamente que os animais da fisioterapia mostraram menor grau de crepitação durante o período experimental. De forma geral, ambos os grupos demonstraram discreto $\mathrm{e}$ progressivo aumento da crepitação na articulação FTP operada ao longo da pesquisa. Em relação à sensibilidade dolorosa, o grupo da imobilização temporária demonstrou sinais mais acentuados nas duas primeiras semanas do pós-operatório.

Quanto às medidas da circunferência da coxa dos membros operados, obtidas nos terços distal, médio e proximal do fêmur, não houve diferença significativa entre os grupos. Os valores obtidos nos terços médio e proximal do fêmur demonstraram que houve, em ambos os grupos, redução importante na massa muscular da coxa da segunda à $14^{\mathrm{a}}$ semana de pós-operatório. Em relação ao membro não-operado, houve aumento progressivo da massa muscular da coxa ao longo das semanas, entretanto sem haver diferença entre os grupos estudados. $\mathrm{Na}$ amplitude de movimentos, os animais submetidos à fisioterapia apresentaram melhor flexão da articulação durante a fase de reabilitação, com diferença significativa entre os grupos nas duas primeiras semanas após a cirurgia. Não houve diferença entre os grupos em relação aos ângulos de extensão da articulação. Em todos os animais, observou-se importante diminuição da amplitude de movimentos da articulação até a oitava semana após a cirurgia, com diferença significativa entre os grupos apenas nas duas primeiras semanas.

Na mensuração do deslocamento cranial da tíbia em relação ao fêmur, não houve alteração significativa ao longo do período pós-operatório. Embora não tenha ocorrido diferença estatística entre os dois grupos, observou-se clinicamente que o grupo da imobilização temporária apresentou continuamente valores mais elevados no teste da gaveta. A avaliação dos animais por meio da plataforma de força mostrou que os cães submetidos à fisioterapia apresentaram melhor apoio do membro operado no pós-operatório do que os animais sob imobilização temporária, principalmente no primeiro mês após a cirurgia, período em que houve diferença significativa entre os grupos. Aos 120 dias após a cirurgia, os grupos I e II apresentaram índices semelhantes de apoio dos membros (Fig. 2).

O exame radiográfico, realizado aos 30 dias após a substituição artroscópica do LCC, possibilitou a identificação de alterações articulares. Nesse período, foram observadas discretas alterações na articulação FTP de dois cães submetidos à fisioterapia e de um cão da imobilização temporária, caracterizadas por efusão articular e osteófitos na extremidade distal da patela. Aos 60 dias de pós-operatório, todos os animais apresentaram alterações radiográficas discretas, como osteófitos nas extremidades da patela e na superfície caudal dos côndilos da tíbia. As alterações tornaram-se mais acentuadas aos 90 dias e, principalmente, aos 120 dias após a cirurgia. Nesse último período, $50 \%$ dos animais do grupo I e $75 \%$ do grupo II mostravam acentuada formação de osteófitos periarticulares (Fig. 3). Baseando-se no sistema de pontuação pré-estabelecido, não houve diferença significativa entre os grupos pesquisados. 
Fisioterapia após substituição...

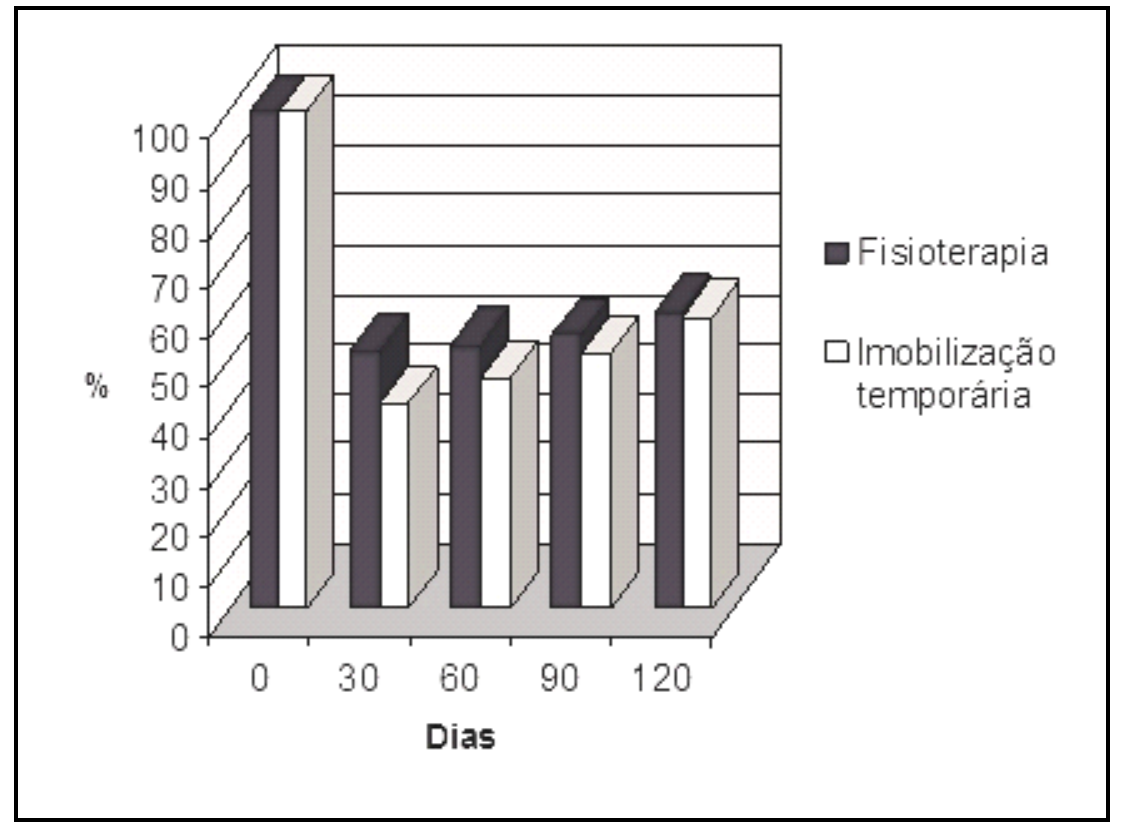

Figura 2. Percentual médio do apoio do membro operado sobre a plataforma de força de cães submetidos à fisioterapia ou imobilização temporária, após a substituição artroscópica do ligamento cruzado cranial. O dia " 0 " representa os valores obtidos no pré-operatório.

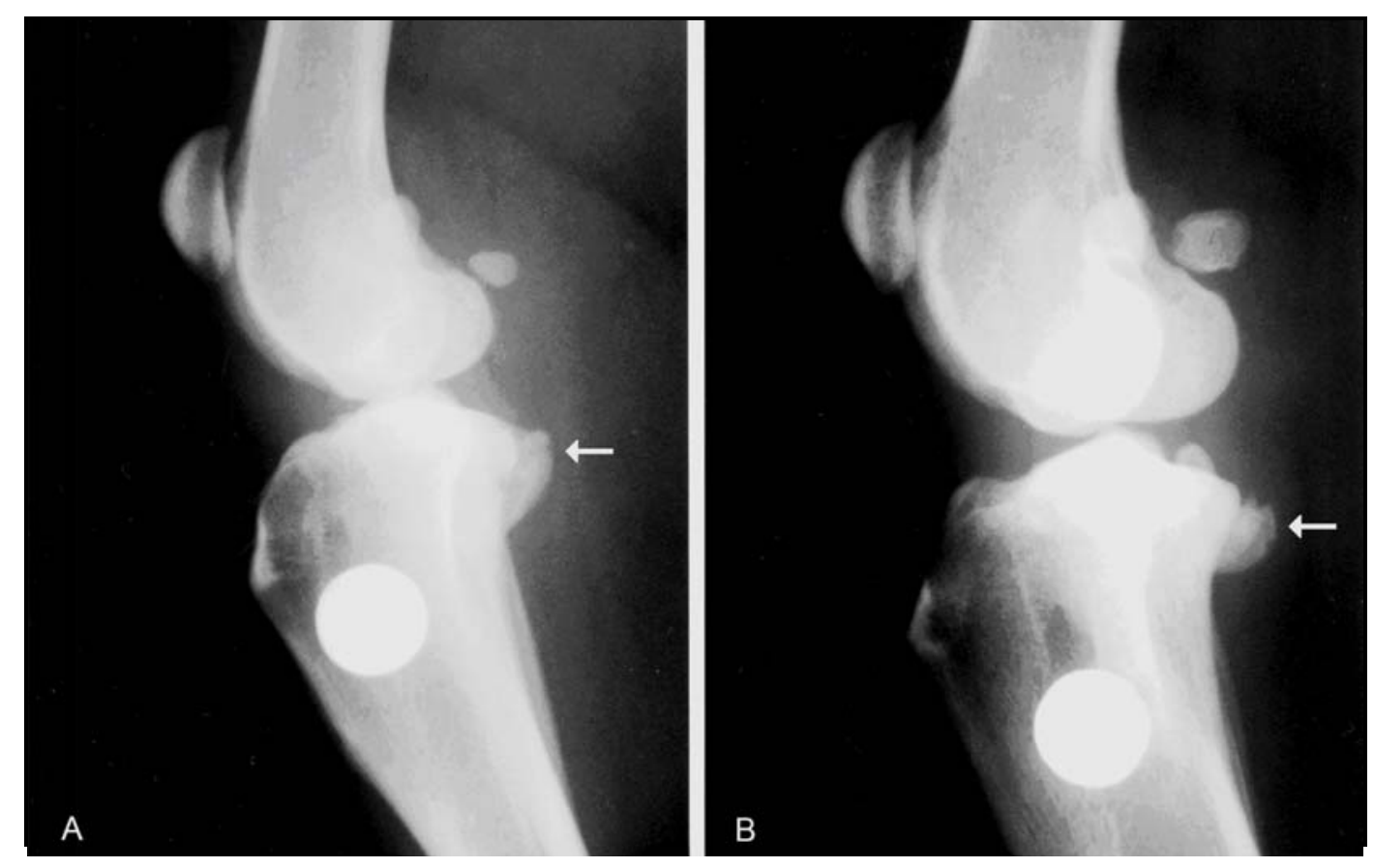

Figura 3. Imagens radiográficas na incidência mediolateral da articulação femorotibiopatelar de cães submetidos à substituição artroscópica do ligamento cruzado cranial. A) cão do grupo da imobilização temporária com osteofitose acentuada na borda caudal do côndilo da tíbia (seta) aos 120 dias após a cirurgia. B) cão do grupo da fisioterapia com osteofitose acentuada na borda caudal do côndilo da tíbia (seta) aos 120 dias após a cirurgia. Em cada imagem, observa-se uma estrutura radiopaca circular no terço proximal da tíbia que corresponde ao parafuso e à arruela. 
Por meio do exame ultrassonográfico, verificouse que cinco animais $(62,5 \%)$ em cada grupo já apresentavam alterações articulares discretas aos 30 dias após a cirurgia, caracterizadas pela distensão do recesso suprapatelar e irregularidades discretas nos côndilos femorais. Aos 60 dias de pós-operatório, todos os animais possuíam alterações ultrassonográficas sugestivas de artrose, que se tornaram mais acentuadas aos 90 e 120 dias. Neste último período de avaliação, seis cães $(75 \%)$ em cada grupo mostravam alterações moderadas na articulação, tais como irregularidades nos côndilos femorais e formação de osteófitos na extremidade da patela e nas fabelas. Pelo sistema de pontuação estabelecido para as características ultrassonográficas, os animais dos dois grupos desenvolveram alterações articulares de forma semelhante.

Ultrassonograficamente, foi possível identificar e avaliar o enxerto da fascia lata no interior articular, que se manteve íntegro e regular em todos os animais. De forma geral, o enxerto apresentou-se como uma estrutura filamentar hipoecoica delimitada pelo tecido adiposo infrapatelar, com dimensões médias de 1,2 x $0,3 \mathrm{~cm}$ e $1,1 \mathrm{x} 0,3 \mathrm{~cm}$ para os grupos da fisioterapia e imobilização temporária, respectivamente. Observou-se discreto e progressivo aumento da ecogenicidade do enxerto ao longo do período avaliado.

\section{DISCUSSÃO}

O resultado favorável mostra que a técnica de substituição do LCC via artroscópica é aplicável também na espécie canina, apesar do tamanho reduzido da articulação. Assim, é possível evitar a artrotomia convencional, promovendo uma recuperação rápida da função do membro no período pós-operatório, como descreveu Person (1987), após realizar a substituição artroscópica do LCC por prótese de fibras de carbono em cães. Segundo Ritchie e Parker (1996), a substituição artroscópica do ligamento cruzado anterior no homem resulta em menor morbidade do mecanismo extensor, menos dor no pósoperatório, menor fibrose articular e proporciona retorno mais rápido da atividade normal do membro. No presente estudo, a grande incisão lateral para se obter o retalho da fascia lata reduz em parte o benefício das pequenas incisões proporcionadas pela artroscopia. Entretanto,
Thorson et al. (1989) e Ritchie e Parker (1996) demonstraram a vantagem de se empregar enxerto autógeno devido à eliminação da reação imunológica que ocorre com os alo e xenoenxertos.

A progressiva melhora na deambulação e no apoio do membro ao longo dos 120 dias após a cirurgia encontra-se dentro do período considerado normal quando se utilizam técnicas intra-articulares para substituição do LCC, de acordo com Geels et al. (2000) e Biasi et al. (2005). O aumento discreto e progressivo da crepitação ao longo das semanas mostra correlação com a formação de osteófitos periarticulares observados radiográfica e ultrassonograficamente. A presença de crepitação, segundo Johnson e Johnson (1993), está relacionada com o desenvolvimento de alterações degenerativas na articulação. Os animais submetidos à fisioterapia apresentaram menor sensibilidade dolorosa na articulação no pós-operatório imediato devido, provavelmente, à terapia com compressas de gelo. Segundo Taylor (1992) e Millis e Levine (1997), a hipotermia local provoca vasoconstrição e diminui a atividade enzimática nos tecidos articulares, reduzindo o edema e a inflamação. Para Taylor et al. (1998), a crioterapia no pósoperatório imediato acelera o retorno às atividades físicas.

A similaridade entre as medidas da circunferência da coxa em ambos os grupos difere das citações de Johnson et al. (1997), que observaram significativo aumento da circunferência da coxa em cães tratados com estímulo elétrico dos músculos após a cirurgia para correção da ruptura do LCC. Segundo Taylor (1992), a eletroterapia atua mais intensamente na muscultura hipotrofiada. Nos animais da pesquisa, não havia hipotrofia muscular pré-operatória, o que reduz a eficácia do tratamento elétrico sobre a musculatura da coxa nos cães submetidos à fisioterapia. No período de reabilitação imediata, é esperado que os animais submetidos à movimentação passiva do membro e estímulo elétrico da musculatura da coxa apresentem maior amplitude de movimentos da articulação operada, conforme também observado por Monk et al. (2006). Os exercícios de movimentação passiva da articulação não impedem a hipotrofia muscular, mas reduzem a formação de contraturas e 
aderências articulares, mantendo a amplitude dos movimentos (Manning et al., 1997).

Um dos objetivos da substituição cirúrgica do LCC rompido é o restabelecimento da estabilidade articular (Conzemius et al., 2005). No presente estudo, é provável que a discreta instabilidade articular, observada ao exame de gaveta, tenha sido suficiente para o desenvolvimento de alterações degenerativas na articulação. Para Elkins et al. (1991) e Moore e Read (1996), independentemente da técnica utilizada para substituição do LCC, nenhuma delas fornece total estabilidade articular, e a maioria dos cães desenvolve a osteoartrose após a cirurgia. Acredita-se que os animais submetidos à fisioterapia tenham apresentado menor grau de instabilidade articular devido à maturação tecidual precoce do enxerto e não pela fibrose periarticular.

Segundo Marsolais et al. (2002) e Monk et al. (2006), a tendência atual é realizar a reabilitação imediata após a cirurgia para substituição do LCC. Estes autores citam que a fisioterapia precoce restabelece rapidamente os movimentos da articulação, diminui a dor e recupera o trofismo muscular. No atual estudo, observou-se, por meio da plataforma de força, que a fisioterapia precoce proporcionou uma recuperação mais rápida do apoio do membro durante o período de reabilitação. Entretanto, aos quatro meses após a cirurgia, os dois grupos apresentavam porcentagem de apoio semelhante nos membros operados, mas ainda distante de alcançar a porcentagem de apoio observada no pré-operatório. Conzemius et al. (2005) estudaram a recuperação da função do membro após a ruptura do LCC e afirmaram que, independentemente da técnica cirúrgica adotada, dificilmente os animais retornam ao apoio normal do membro sobre a plataforma de força.

Radiograficamente, a observação do aumento progressivo dos osteófitos periarticulares após a cirurgia para substituição do LCC sugere o desenvolvimento de doença articular degenerativa, conforme descrito por Glyde et al. (2002) e Penha et al. (2007). Nos estudos que testaram a eficácia de diferentes técnicas intra e extra-articulares para reparação do LCC rompido, observou-se radiograficamente o desenvolvimento progressivo de lesões degenerativas em todas elas, demonstrando que não há uma técnica capaz de impedir a progressão da osteoartrose (Moore e Read, 1995; Geels et al., 2000). No presente estudo, a semelhança entre os grupos quanto à presença de lesões degenerativas avaliadas ao exame radiográfico demonstra que a utilização do programa de fisioterapia implementado logo após a cirurgia não influencia na formação dos osteófitos periarticulares. Além disso, observa-se que os achados radiográficos não se correlacionam com a melhora clínica da claudicação e apoio do membro, como também descrito por Coetzee e Lubbe (1995) e Penha et al. (2007), que não observaram relação entre o grau de claudicação e a intensidade de formação dos osteófitos após a substituição do LCC.

Os resultados mostraram que a ultrassonografia permite a identificação precoce dos osteófitos periarticulares em relação ao exame radiográfico. Para Dupuis e Harari (1993), a formação de osteófitos pode ser observada radiograficamente após quatro semanas da secção do LCC, tempo semelhante ao observado neste estudo. Entretanto, não foram encontrados dados na literatura consultada a respeito da precocidade do exame ultrassonográfico para detecção dos sinais de osteoartrose após a instabilidade articular. Segundo Muzzi et al. (2002), a ultrassonografia é eficaz para a identificação de osteófitos nos côndilos femorais. Gnudi e Bertoni (2001) citaram que o ultrassom é adequado para se avaliar as alterações dos tecidos moles decorrentes da instabilidade articular, fato também observado na atual pesquisa. Conforme observado neste estudo, é possível acompanhar a integridade do enxerto da fascia lata no interior articular por meio da ultrassonografia. Além disso, pode-se avaliar a ecogenicidade do enxerto, que se torna discreta e progressivamente aumentada. Este aumento progressivo da ecogenicidade observado ao ultrassom correlaciona-se com a maturação e deposição de colágeno no enxerto.

\section{CONCLUSÕES}

A cirurgia artroscópica é uma técnica eficaz para a substituição do ligamento cruzado cranial em cães, apesar de não impedir o desenvolvimento da doença articular degenerativa. A fisioterapia, empregada no pós-operatório imediato para substituição do ligamento cruzado cranial, promove melhor estabilidade articular e permite 
a recuperação mais rápida no apoio do membro durante o período de reabilitação. Após a substituição artroscópica do ligamento cruzado cranial em cães, a físioterapia não influencia na progressão das lesões articulares degenerativas observadas radiográfica e ultrassonograficamente.

\section{REFERÊNCIAS BIBLIOGRÁFICAS}

BIASI, F.; RAHAL, S.C.; VOLPI, R.S. et al. Reconstrução do ligamento cruzado cranial em cães, associado ou não ao sulfato de condroitina. Arq. Bras. Med. Vet. Zootec., v.57, p.442-447, 2005

COETZEE, G.L.; LUBBE, A.M. A prospective study comparing two fascial reconstruction techniques to stabilize the cranial cruciate deficient stifle in the dog. Vet. Comp. Orthop. Traumatol., v.8, p.82-90, 1995

CONZEMIUS, M.G.; EVANS, R.B.; BESANCON, M.F. et al. Effects of surgical technique on limb function after surgery for rupture of the cranial cruciate ligament in dogs. $J$. Am. Vet. Med. Assoc., v.226, p.232-236, 2005.

DUPUIS, J.; HARARI, J. Cruciate ligament and meniscal injuries in dogs. Compend. Contin. Educ. Pract. Vet., v.15, p.215-233, 1993

ELKINS, A.D.; PECHMAN, R.; KEARNEY, M.T. et al. A retrospective study evaluating the degree of degenerative joint disease in the stifle joint of dogs following surgical repair of anterior cruciate ligament rupture. J. Am. Anim. Hosp. Assoc., v.27, p.533-540, 1991

EUCLYDES, R.F. Manual de utilização do sistema SAEG, versão 7. Viçosa: UFV, 1999.

GEELS, J.J.; ROUSH, J.K.; HOSKINSON, J.J. et al. Evaluation of an intracapsular technique for the treatment of cranial cruciate ligament rupture. Vet. Comp. Orthop. Traumatol., v.13, p.197-203, 2000.

GLYDE, M.R.; WONG, W.T.; LIDBETTER, D. et al. Partial rupture of the cranial cruciate ligament in 13 dogs: clinical, radiological, clinicopathological and histopathological features. Ir. Vet. J., v.55, p.271-276, 2002.

GNUDI, G.; BERTONI, G. Echographic examination of the stifle joint affected by cranial cruciate ligament rupture in the dog. Vet. Radiol. Ultrasound, v.42, p.266-270, 2001.

HAYASHI, K.; MANLEY, P.A.; MUIR, P. Cranial cruciate ligament pathophysiology in dogs with cruciate disease: a review. J. Am. Anim. Hosp. Assoc., v.40, p.385-390, 2004

HODGES, C.C.; PALMER, R.H. Postoperative physical therapy. In: HARARI, J.H. (Ed.). Surgical complications and wound healing in the small animal practice. Philadelphia: Saunders, 1993. p.389-405

JOHNSON, J.M.; JOHNSON, A.L. Cranial cruciate ligament rupture: pathogenesis, diagnosis and postoperative rehabilitation. Vet. Clin. N. Am.: Small Anim. Pract., v.23, p.717-733, 1993
JOHNSON, J.M.; JOHNSON, A.L.; PIJANOWSKI, G.J. et al. Rehabilitation of dogs with surgically treated cranial cruciate ligament-deficient stifles by use of electrical stimulation of muscles. Am. J. Vet. Res., v.58, p.1473-1478, 1997.

KUDNIG, S.T. Cruciate ligament rupture: intra-articular replacement. Aust. Vet. J., v.78, p.384-385, 2000.

MANNING, A.M.; RUSH, J.; ELLIS, D.R. Physical therapy for critically ill veterinary patients. Part II. The musculoskeletal system. Compend. Contin. Educ. Pract. Vet., v.19, p.803-807, 1997

MARSOLAIS, G.S.; DVORAK, G.; CONZEMIUS, M.G. Effects of postoperative rehabilitation on limb function after cranial cruciate ligament repair in dogs. J. Am. Vet. Med. Assoc., v.220, p.1325-1330, 2002.

MILLIS, D.L.; LEVINE, D. The role of exercise and physical modalities in the treatment of osteoarthritis. Vet. Clin. N. Am.: Small Anim. Pract., v.27, p.913-930, 1997.

MONK, M.L.; PRESTON, C.A.; MCGOWAN, C.M. Effects of early intensive postoperative physiotherapy on limb function after tibial plateau leveling osteotomy in dogs with deficiency of the cranial cruciate ligament. Am. J. Vet. Res., v.67, p.529-536, 2006

MOORE, K.W.; READ, R.A. Cranial cruciate ligament rupture in the dog - a retrospective study comparing surgical techniques. Aust. Vet. J., v.72, p.281-285, 1995.

MOORE, K.W.; READ, R.A. Rupture of the cranial cruciate ligament in dogs. Part II. Diagnosis and management. Compend. Contin. Educ. Pract. Vet., v.18, p.381-391, 1996.

MUZZI, L.A.L.; REZENDE, C.M.F.; MUZZI, R.A.L. et al. Ultrasonography of the stifle joint in dogs with cranial cruciate ligament rupture. In: SEMANA DE PÓSGRADUAÇÃO DA UFMG, 3., 2002, Belo Horizonte. Anais... Belo Horizonte: UFMG, 2002. CD-ROM.

PENHA, E.M.; REZENDE, C.M.F.; MELO, E.G. et al. Pósoperatório tardio da substituição do ligamento cruzado cranial no cão. Arq. Bras. Med. Vet. Zootec., v.59, p.1184-1193, 2007

PERSON, M.W. Prosthetic replacement of the cranial cruciate ligament under arthroscopic guidance. A pilot project. Vet. Surg., v.16, p.37-43, 1987.

RITCHIE, J.R.; PARKER, R.D. Graft selection in anterior cruciate ligament revision surgery. Clin. Orthop. Relat. Res., v. 325, p. $65-77,1996$

TAYLOR, R.A. Postsurgical physical therapy: the missing link. Compend. Contin. Educ. Pract. Vet., v.14, p.1583-1594, 1992

TAYLOR, R.A.; LESTER, M.; GANNON, J.R. Physical therapy in canine sporting breeds. In: BLOOMBERG, M.S; DEE, J.F.; TAYLOR, R.A. (Eds). Canine sports medicine and surgery. Philadelphia: Saunders, 1998. p.265-274.

THORSON, E.; RODRIGO, J.J.; VASSEUR, P. et al. Replacement of the anterior cruciate ligament - a comparison of autografts and alldografts in dogs. Acta Orthop. Scand., v.60, p.555-560, 1989. 